\title{
Cooperating to Resist Coercion: An Experimental Study
}

\author{
Lucy F. Ackert \\ Department of Economics and Finance \\ Michael J. Coles College of Business \\ Kennesaw State University \\ 1000 Chastain Road \\ Kennesaw, GA 30144 \\ ph: 770-423-6111 \\ fax: 770-499-3209 \\ email: lackert@kennesaw.edu
}

\author{
Ann B. Gillette \\ Department of Economics and Finance \\ Michael J. Coles College of Business \\ Kennesaw State University \\ 1000 Chastain Road \\ Kennesaw, GA 30144 \\ ph: 770-499-3278 \\ fax: 770-499-3209 \\ email: agillet1@kennesaw.edu
}

\author{
Mark Rider \\ Department of Economics and \\ International Studies Program \\ Andrew Young School of Policy Studies \\ Georgia State University \\ Atlanta, GA 30303 \\ ph: (404) 413-0227 \\ fax: (404) 651-0234 \\ email: mrider@gsu.edu
}

January 31, 2011

The views expressed here are those of the authors and not necessarily those of the Federal Reserve Bank of Atlanta of the Federal Reserve System. The authors gratefully acknowledge the financial support of the Federal Reserve Bank of Atlanta, Georgia State University, and Kennesaw State University. We would like to thank Cynthia Hosford, Astha Sen, and Yujia Wang for outstanding research assistance. We also are grateful to Jorge Martinez-Vazquez, Luc Noiset, Arno Riedl, Stanley Winer, and participants at the Coercion and Social Welfare in Contemporary Public Finance Conference for insightful comments and discussions. 


\title{
Cooperating to Resist Coercion: An Experimental Study
}

\begin{abstract}
This study sheds light on the difficulties people face in cooperating to resist coercion. We adapt a threshold public goods game to investigate whether people are able to cooperate to resist coercion despite individual incentives to free-ride. Behavior in this resistance game is similar to that observed in multi-period public goods games. Specifically, we observe "out-of-equilibrium” outcomes and a decrease in successful resistance in later periods of a session compared to earlier ones. Nevertheless, cooperation remains relatively high even in the later periods. Finally, we find that increasing the resistance threshold has a substantial negative effect on the probability of successful resistance.
\end{abstract}

Keywords: Coercion, Equity, Social preferences

JEL Classification numbers : C91, C92, D63, H21 
Liberal-democratic states often pursue coercive policies. Congleton (2011), Skaperdas (2011), and Wallis (2011) describe ways other than actual physical force in which coercion may arise in such regimes through tax, expenditure, and regulatory policies. For example, the collective choice to supply any given quantity of a public good, which lies at the very heart of public policy, implicitly involves coercion when a uniform tax-price is used to finance the public good in the presence of heterogeneous tastes. ${ }^{1}$ Individuals with heterogenoues tastes for a public good will demand different quantities of the good at any given tax-price. Due to the nature of a pure public good, however, everyone must consume the same quantity. Therefore, government is implicitly coercing some people to consume more (less) than their optimal quantity of the public good at the given tax-price. ${ }^{2}$

In authoritarian regimes, liberal-democratic regimes, and totalitarian regimes alike, people may seek to overturn government actions with which they disagree, i.e., coercive government actions. The manner in which citizens can legitimately express resistance to government action and the criteria for determining successful resistance depends on, among other things, the nature of the regime. Generally speaking, however, resisting government action is costly to individuals in terms of time, money, and possibly one's very well-being. To succeed, typically resistance must exceed a threshold --- a tipping point. There may be formal and explicit

\footnotetext{
${ }^{1}$ More specifically, Winer (2011) provides a cardinal measure of coercion in this context using Lindahl prices as a reference point and Martinez-Vazquez and Sehili (2011) provide an interesting application of this measure of coercion using a computable general equilibrium model.

${ }^{2}$ In economics, a pure pubic good is non-rival in consumption and non-exclusive. Therefore, everyone must consume the same quantity of it. An example of pure public goods is national defense. The assumption that everyone pays a uniform tax-price for the public good is made to simplify the discussion. This assumption could be relaxed to allow for a variety of tax prices. Technically speaking, Winer et al. (2011) contend that there is coercion if their marginal rate of substitution for the public good is different from the tax-price that they pay to the government to provide it.
} 
rules describing the threshold for successful resistance (i.e., majority rule in liberal-democratic regimes) or arbitrary and implicit rules (i.e., intolerable level of social unrest), particularly in authoritarian and totalitarian regimes.

In any event, the threshold, whatever it may be, can be achieved either through large contributions of time, money, and effort by a few individuals or through small contributions of the same by many. Since a commitment device is typically not available, a substantial coordination problem arises when trying to rally public support to resist unpopular government actions. Cooperating to resist government action is similar to cooperating to provide a public good. With this highly stylized description of resisting coercive government action in mind, we adapt a public goods game to investigate whether people are able to cooperate to resist coercion. For this purpose, we use a resistance game, similar to the one used by Mertins (2008) to examine procedural justice.

In our version of a resistance game, a randomly chosen, anonymous, decision-maker (DM) is given the opportunity to expropriate all or part of the experimental endowments of 4 experimental subjects, henceforth referred to as “Others.” Others can resist a DM's transfer demand by making voluntary contributions to a resistance fund. If the resistance fund balance (RFB) equals or exceeds a pre-determined, common knowledge threshold, the Others are not required to pay the DM's transfer demand. If, however, the RFB does not equal or exceed the resistance threshold, then resistance is unsuccessful, and the Others are required to pay the DM's transfer demand. Whether or not resistance is successful, the Others lose their contributions to the resistance fund.

Presumably one's contribution to the resistance fund is the result of the interplay between (1) the intensity of one's desire to resist a given transfer demand, and (2) one's subjective beliefs 
regarding the amount that the remaining members of the group will contribute to the fund. As in the real world, allowing particpants to make differing contributions to the resistance fund reflects the fact that the cost of resistance is typically a continuous choice variable in terms of time, money, and perhaps physical risk and not a simple binary choice variable.

Due to the non-exclusive nature of successful (or unsuccessful) resistance, cooperating to resist government action creates a social dilemma, as in the case of voluntary provision of a public good. In the context of our game, Others are collectively better off when 'out of equilibrium' transfer demands by DMs are successfully resisted. ${ }^{3}$ However, a subject in this game can gain a private advantage from not contributing to the resistance fund and free-riding on successful resistance financed by the remaining members of the group. The inability to exclude those who do not contribute to the resistance fund from enjoying the benefit of successful resistance creates the social dilemma and thus exacerbates the coordination problem in our resistance game.

The goal of this paper is to investigate the ability of subjects to cooperate to resist coercive expropriation of their experimental endowments by a randomly selected, anonymous DM. Specifically, we examine the interplay between increasing the resistance threshold on the size of a DM's transfer demand and the ability of Others to cooperate in resisting expropriation of their experimental endowment. Summarizing our main results, DMs generally pursue "out-ofequilibirum" strategies, and Others only enjoy partial success in resisting these transfer demands. Consequently, the observed average earnings of DMs is substantially greater than that predicted

\footnotetext{
${ }^{3}$ An out-of-equilibrium transfer demand is one that exceeds the resistance threshold divided by the number of Others. More specifically, suppose the resistance threshold is 13 francs, and there are 4 Others. As discussed in greater detail below, the equilibrium transfer demand in this example is 3 francs. Others should not contribute to resist a transfer demand less than the equilibrium value of 3 francs because successful resistance would cost them more than simply paying the DM's transfer demand.
} 
by the theory. We find this, despite the fact that the forecasts of the RFB by Others is remarkably accurate. We also find evidence that the probability of resistance decreases in later rounds of a session as compared to the probability of resistance in the initial rounds. Finally, increasing the resistance threshold from 13 francs to 29 francs has a substantial positive effect on a DM's average transfer demand; a substantial negative effect on the probability of resistance; and a positive (negative) effect on the earnings of DMs (Others).

The remainder of the paper is organized as follows. In the next section, we describe the resistance game in greater detail. In the subsequent section, we provide a detailed discussion of our empirical findings. The final section concludes.

\section{EXPERIMENTAL DESIGN AND METHOD}

This experiment consists of two resistance level treatments, and five total sessions. Each session consists of 15 university students for a total of 75 subjects in the entire experiment ${ }^{4} .$. All trading is in francs, an experimental currency, which is converted into U.S. dollars at a rate of 1 franc $=\$ 0.20$ or 5 francs $=\$ 1.00$ for purposes of paying the subjects. Subjects are undergraduate and graduate students with a variety of majors. All are inexperienced subjects, in that none participated in a previous experiment with similar design and each subject participated in only one session of our expriment. Participants earn from $\$ 12.40$ to $\$ 130.80$ in the experiment, with average earnings of $\$ 49.40 .^{5}$ Each session took approximately two hours to complete. Based on our observations, the participants appeared to be motivated by the monetary rewards.

\footnotetext{
${ }^{4}$ Two DMs and two Others do not report their marital status, so they are excluded from the regression analysis

${ }^{5}$ A participant's total compensation includes a $\$ 2$ bonus for being on time and $\$ 4$ for completing a post-experiment questionnaire. All 75 participants received the additional compensation of $\$ 6$.
} 
Upon arrival at the designated time and place of the experiment, subjects receive a set of instructions which the experimenter read aloud. ${ }^{6}$ Subjects were encouraged to ask clarifying questions, and the experimenters conducted a few practice periods to make sure everyone understood the instructions. Each session consists of 10 (8) decision periods. ${ }^{7}$ The 15 participants in a given session are randomly and anonymously assigned to one of three groups of five subjects each. One member of each group is randomly designated the DM; the remaining 4 group members are henceforth referred to as Others. As explained in the instructions, the membership of each group of 5 and their respective roles in each group are pre-randomized by the experimenter. Participants of the 3 groups and their respective roles in each group remain the same throughout a session. Members of a group do not know the identity of the members of their group, and they do not know one anothers’ roles, i.e., DM or Other.

At the beginning of each decision period, all subjects are endowed with 25 francs (\$5.00). As mentioned earlier, our experimental design is most similar to a more complex procedural justice design used by Mertins (2008). Little resistance occurred in that study. Although there are other design differences, we believe the the primary reason there is more resistance in our experiment is the reference frame of the DM. The DM in Mertins' study had no initial endowment and thus no earnings from the experiment unless he solicits and received funds from the Others. If the Others are averse to such inequities, then they may not resist transfer demands by DMs which make the distribution of payoffs among the subject more equal. To avoid this induced reference frame, we gave our DMs the same initial endowment as the Others.

\footnotetext{
${ }^{6}$ The instructions are included in an appendix to this paper.

${ }^{7}$ Though our intention was to include 10 rounds in each session, the first session only included 8 rounds because we ran short of time.
} 
The DM of each group then announces a transfer demand to the Others in his group; the DM's proposed transfer demand is the same for all 4 Others. For example, suppose the DM makes a transfer demand of 5 francs. Ignoring for the moment the ability of Others to resist such demands, 5 francs would be subtracted from the endowment of each of the 4 group members thus resulting in a total transfer demand of 20 francs. Upon receiving the DM's transfer demand, the Others then decide whether and how much to contribute to the resistance fund. An Other can pay any number of francs into the group’s resistance fund. To resist paying a DM's transfer demand, the RFB must equal or exceed a pre-determined threshold. During each period, the experimenter calculates the RFB for each of the 3 groups. If during a a given period in treatment 1 of the experiment, a group’s RFB equals or exceeds 13 francs (\$2.60), the group’s resistance is declared successful, and the Others in this group are not required to pay the DM's transfer demand. If, however, a group’s RFB is less than 13 francs, the Others lose their contributions to the fund and must also pay the DM's transfer demand. In addition to three sessions of treatment 1 described above, we also conduct two sessions of treatment 2, with a resistance threshold of 29 francs $(\$ 5.80)$.

Before learning the group’s RFB during a given period, all subjects (the DMs and Others) are asked to forecast the RFB for that period, and subjects receive $\$ 0.25$ each period for recording a forecast. After forecasts are recorded, the total fund balance of each group is announced to the participants. However, they are not told the amount contributed by individual members of their group. After learning whether resistance was successful or not, the subjects calculate their period earnings. The subsequent periods repeat these steps, with all subjects beginning each period with a fresh endowment of 25 francs. After completing the 10 (8) decision periods, participants complete a post-experiment questionnaire that includes demographic 
questions as well as questions regarding their reaction to the experiment. To motivate thoughtful responses, they receive $\$ 4$ for completing the questionnaire. After completing the questionnaire, the experimenters pay the subjects privately in cash.

In a one-shot version of this game with a resistance threshold of 13 (29) francs, the efficient, subgame perfect equilibrium strategies are the following: 1.) the DM makes a transfer demand of 3 (7) francs, and 2.) the Others contribute nothing to the resistance fund. Using backward induction, the equilibrium strategies of a multi-period version of this game is the same as for the one-shot version. Since the two resistance thresholds - 13 and 29 francs -- are not evenly divisible by 4 , the game does not have a unique equilibrium. For example, with a threshold of 13 frances, 3 subjects could contribute 3 francs and the remaining subject would have to contribute 4 francs to resist a DM's transfer demand. Thus, there are 4 equilibrium strategies: $\left(\mathrm{T} ; \mathrm{C}_{1}, \mathrm{C}_{2}, \mathrm{C}_{3}, \mathrm{C}_{4}\right)=(3 ; 4,3,3,3),(3 ; 3,4,3,3),(3 ; 3,3,4,3)$, and $(3 ; 3,3,3,4)$, where $\mathrm{T}$ is the DM's transfer demand and $C_{\mathrm{i}}$ is Other i's $(=1, . ., 4)$ contribution to the resistance fund. This feature of the experiment makes coordination by the Others on the efficient, subgame perfect equilibrium strategy more difficult because one and only one member of the group should step forward and make the higher contribution to the resistance fund.

Assuming that all subjects employ equilibrium strategies throughout the sessions, a DM's total payoff in treatment 1 (2) would be 280 (320) francs or \$56 (\$74), and the total payoff to an Other in treatment 1 (2) would be 220 (180) francs or $\$ 44$ (\$26). We proceed below with a detailed discussion of our findings.

\section{SUMMARY OF FINDINGS}

This section is organized as follows. We begin by briefly discussing the descriptive statistics of our sample. Next, we discuss the frequency distribution of transfer demands and the 
frequency distribution of successful resistance, conditional on the transfer demand. Then, we discuss the results of our econometric models of the DM's and Other's decisions or strategy choices. Finally, we discuss the frequency distribution of correct forecasts of resistance.

Table 1 reports the descriptive statistics for our sample of 719 decisions by 75 subjects. The sample consists of 144 transfer demands by 15 DMs and 575 contribution decisions by 60 Others. Of the 15 DMs, 9 participate in treatment 1, making 84 transfer demands, and 6 participate in treatment 2, making 60 transfer demands. Meanwhile, 36 Others participate in treatment 1 and 24 in treatment 2, making 335 and 240 contribution decisions, respectively. The average transfer demand is 9.85 francs, and the average transfer demand is greater in treatment 2 than in treatment 1 . The average contribution to the resistance fund is 4.02 francs. Again, the average contribution is slightly greater in treatment 2 than in treatment 1 . However, the average contribution in treatment 1 , when multiplied by 4 , exceeds the resistance threshold of treatment 1. In contrast, the average contribution in treatment 2 when multiplied by 4 , does not exceed the resistance threshold of treatment 2 .

Slightly less than 46 percent of all transfer demands are resisted. Substantially more transfer demands in treatment 1 are resisted than in treatment 2, specifically 56 percent versus 33 percent, respectively. Interestingly, the average forecast error of the RFB during each period is surprisingly small, approximately 2 francs for Others and 0.29 francs for DMs. The average age of Others (DMs) is 24 (24) years old; 48 (79) percent are white; 50 (39) percent are Christian; 11 (16) percent are married; and 54 (75) percent are female.

Turning to average earnings, DMs earn on average 393.75 francs (\$78.75), and Others earn on average 156.26 francs (\$31.25). In treatment 1, the average earnings of DMs is 312.67 
francs (\$62.53) and 181.30 francs (\$36.26) for Others. In treatment 2, average earnings are 482.84 francs (\$96.57) and 136.43 francs (\$27.29) for DMs and Others, respectively.

These patterns generally are as expected. Due to the power advantage of the DMs in this game, they make more on average than the Others, irrespective of the resistance threshold. As previously discussed, increasing the resistance threshold lowers the probability of resistance. Anticipating this apparently, DMs increase their average transfer demand. That combined with a lower probability of resistance results in DMs earning more on average in treatment 2 than in treatment 1; meanwhile, Others earn less in treatment 2 than in treatment 1 . As a result, the average earnings differential between DMs and Others is 3.5 in treatment 2 as compared to 1.7 in treatment 1 . In other words, increasing the resistance threshold by nearly 125 percent (from 13 to 29 francs) results in a 100 percent increase in the earnings differential between DMs and Others.

It is also interesting to compare the observed earnings, described above, with those predicted by the theory. As previously discussed, assuming subjects employ equilibrium strategies, a DM’s session earnings would be 280 (320) francs or \$56 (\$64) in treatment 1 (2), and the comparable figures for Others are 220 (180) francs \$44 (\$36) in treatment 1 (2). Comparing these figures with the observed session averages for our subjects, we find that the average session earnings of DMs is substantially greater than than that predicted by the theory, and the average session earnings of Others is substantially less than that predicted. However, the actual earnings differential between DMs and Others observed in our experiment for each treatment is greater than the predicted values for each treatment. According to the theory, increasing the resistance threshold should increase the earnings differential by 40 percent, but the observed increase is 100 percent. 


\section{Transfer demands and resistance}

Figures 1 through 3 show the frequency distribution of transfer demands (in francs) and the frequency of resistance, conditional on the transfer demand, for all subjects, for treatment 1 subjects, and for treatment 2 subjects, respectively. Figure 1 shows that the frequency distribution of DM's transfer demands has modes at 10 francs, 15 francs, 20 francs, and 25 francs, suggesting perhaps that numbers evenly divisible by 5 are focal points for purposes of choosing a transfer demand. Interestingly, the distribution of transfer demands appears to be approximately uniform between 1 and 8 francs in figure 1 , and as we subsequently show in figures 2 and 3, as well. The median transfer demand for all DMs is 9 francs.

Comparing figures 2 and 3 allows us to examine the effect of increasing the threshold on the frequency distribution of transfer demands and the ability of Others to resist such demands. Generally speaking, the frequency distributions of transfer demands in figures 2 and 3 exhibit the same general features as those of figure 1. Specifically, the distributions are approximately uniform between 1 and 8 francs, and there are modes in both figures for transfer demands of 10 , 15, 20, and 25 francs, as before. The median transfer demand for treatment 1 is 8 francs ( $\$ 1.80$ ) and, for treatment 2, 10 francs (\$2.00). This increase in the median transfer demand in treatment 2 relative to treatment 1 implies that DMs are responding to the increase in the threshold by increasing their average transfer demand. This suggests that they have some insight into how the parameters of the game are influencing the strategic choices of Others. Furthermore, as the theory suggests, very few transfer demands in treatment 1 (2) less than 3 (7) francs are resisted, meaning that in such cases the RFB does not exceed the resistance threshold. In treatment 1 , nearly all transfer demands greater than 10 francs are resisted. In treatment 2, however, Others are not as successful as the treatment 1 subjects in resisting transfer demands greater than 10 . 
This suggests that increasing the resistance threshold makes it more difficult for Others to coordinate to resist transfer demands. The increase in the difficulty of cooperating to resist transfer demands from increasing the resistance threshold also is reflected in the decrease in average period earning by Others in treatment 2 as compared to that of treatment 1 . The average period earnings by Others in treatments 1 and 2 are 19.48 francs (\$3.90) and 13.79 francs (\$2.76), respectively.

While we can take reassurance from the fact that the theory explains some patterns in our data, it is also clear that DMs choose "out of equilibrium" strategies more often than not. This is consistent with previous findings in related literatures: “out of equliliburim”strategies are not unusual in experimental studies with repeated play. The DM may be learning about the probability of resistance by trying to separate individual preferences and group coordination issues. Furthermore, the ability to resist 'outsized' transfer demands - those greater than the resistance threshold divided by 4 - in our data is substantially greater than suggested by the theory which predicts that the Others will make no contribution to the resistance fund. In other words, in the theory, everyone will try to free-ride and resistance of out-sized transfer demands will always fail.

Modeling the strategy choices of DMs and Others

In this section, we briefly discuss the results of econometric models describing the strategy choices of DMs and Others. The estimates of these two models are reported in tables 2 and 3, respectively.

Beginning with our model of the DMs strategy choice, we estimate a random effects model in which the dependent variable is the DMs' tranfer demand (in francs). We include demographic characteristics of the DM (i.e., gender, martial status, age, age-squared, and a 
dummy variable for white) in the model to control for unobserved differences in tastes that may influence their strategy choices. We are assuming that such tastes may be correlated with certain demographic characteristics of the subject. We estimate a random effects model to account for unobserved differences in tastes that are uncorrelated with observables, such as race, gender, age, religion, and so on. In order for our estimates to be consistent, the distribution of the unobservable, random taste variable must be normally distributed. We find that the estimated coefficients of age and race are negative and statistically significantly different from zero at conventional levels. ${ }^{8}$

We also include characteristics of the game and treatments among the regressors to control for monetary incentives embedded in the game. Specifically, we include among the regressors lagged transfer demands to account for "learning-by-doing," the DM's forecast of the the RFB, the lagged forecast error, and resistance in the previous period. By including a dummy variable equal to 1.0 for treatment 2 , we are able to examine the effect of changing the resistance threshold on the strategy choices of DMs which is a focus of this regression. Somewhat surprising, this indicator variable is negative but statistically indistinguishable from zero at conventional levels. Among the incentive variables, only the lagged transfer demand is statistically significantly different from zero at conventional levels. It is positive, suggesting that DMs increase their transfer demand in subsequent periods.

Turning to our results for the strategy choices of those assigned to the role of Others, we also estimate a random effects model to account for unobserved tastes that may influence strategy choices. In two specifications of this model, we estimate Two-Stage Least Squares

\footnotetext{
${ }^{8}$ We report clustered standard errors, clustering on the identity of the decision-maker (DMs and Others, as the case may be) to account for the fact that a set of observations apply to one individual and thus these observations may not be independently distributed.
} 
(2SLS) to account for the potential endogeneity of the variable "correctly forecasting whether or not the RFB equals or exceeds the resistance threshold." We use the lagged value of the forecast as an instrumental variable for this potentially endogeneous variable. For comparision purposes, we also report OLS estimates which are reported in column 1 of table 3. Finally, we estimate two specifications of the 2SLS model, one specification includes a set of race indicator variables (i.e., Black, Hispanic, and Asian), and the other specification does not include this set of indicator variables. These results are reported in columns 2 and 3, respectively, of table 3.

Beginning with the OLS estimates, the only variable that is statistically distinguishable from zero at conventional levels is the tranfer demand. The estimated coefficient is equal to 0.219 (S.E. $=0.0242$ ), and the estimate is nearly ten times its standard error. This estimate suggests that there is a positive relationship between the transfer demand and the size of the Others contribution to the resistance fund.

Now, we turn to the 2SLS estimates reported in column 3. In contrast to our OLS specification, this model includes an indicator variable for correctly forecasting resistance. Since this variable is potentially endogeneous, we estimate the model using 2SLS. The instrumental variable is the lagged forecast of the RFB. The estimated coefficient of this variable is positive and more than twice it standard error. This estimate suggests that there is a positive relationship between a correct forecast of resistance and the size of the contribution to the resistance fund. The estimated coefficient of the threshold indicator variable is positive and statistically significant at the 1 percent level, meaning that the average contribution in treatment 2 is greater than in treatment 1 due to the increase in the resistance threshold. Finally, the estimated coefficient of marital status ( $=1$ if single) is positive and statistically significant, suggesting that single subjects contribute more on average to the resistance fund than their married counterparts. 


\section{Distribution of RFB forecast accuracy}

Now, we examine the forecasts of the RFB by the subjects in this experiment. Figures 4 through 6 show the distributions of forecast accuracy for all subjects, treatment 1 subjects, and treatment 2 subjects, respectively. The horizontal axis of these figures categorizes subjects according to the proportion of times a given subject correctly forecasts whether or not the RFB would or would not equal or exceed the threshold.

As previously noted, the forecast error of the RFB is remarkably small. This is borne out in table 4 which shows that approximately 55 subjects out of 75 are correct more than 40 percent of the time. Figures 5 and 6 show the distribution of forecast accuracy of subjects in treatments 1 and 2, respectively. The main distinguishing feature of these two distributions is that there is evidence of some deterioration in the ability of subjects to make correct forecasts under treatment 2 as compared to their ability in treatment 1. In other words, increasing the threshold appears to have adversely affected the ability of participants to correctly forecast whether or not resistance will be successful.

\section{Odds and ends}

We are interested to know whether the main behavioral patterns observed in public goods games also are observed in the resistance game that is the focus of this study. Two features of multi-period public goods games are particularly noteworthly in the current context. ${ }^{9}$ Specifically, there is considerably more giving in public goods games than predicted in the hardnosed Nash equilibrium, and cooperation in multi-period public goods games appears to deteriorate in later rounds of a session. We also find substantial evidence of “out-of-equilibrium'

\footnotetext{
${ }^{9}$ See Ledyard (1996) for a detailed review of this literature.
} 
play in our resistance game. DMs demand substantially more than predicted by the theory, and Others are more successful in resisting 'outsized' transfer demands than predicted by the theory.

We also examine whether there is a decline in cooperation among Others in later periods of a session as compared to earlier periods. In the first five periods of a session, Others successfully resist transfer demands 54 percent of the time, compared to 41 percent of the time in the last 5 rounds of a session. This observations suggests that, as in a multi-period public goods game, there is some deterioration in the ability of Others to cooperate to resist transfer demands.

For treatment 1, the corresponding figures are 64 percent and 48 percent, and for treatment 2, the figures are 37 percent and 30 percent. There is a decline in the ability of Others to resist coercion in later rounds of the game, compared to their ability in earlier rounds. Nevertheless, the ability to resist remains rather high even in the later rounds. Second, the ability to cooperate in resisting transfer demands is much greater when the threshold is smaller than when it is greater.

Curiously, the decline in the ability to cooperate between the first five periods and the last five periods of a session is steeper in treatment 1 (-26 percent) compared to treatment 2 (-18 percent).

\section{CONCLUSION}

We adapt a public goods game to investigate whether people are able to cooperate to resist coercive government actions in the face of individual incentives to do otherwise. For this purpose, we use a resistance game which is a form of threshold public goods game. The equilibrium strategy in this game is for a DM to make a modest transfer demand of 3 (7) francs in treatment 1 (2) and for Others to offer no resistance to such demands. In the case of "out of equilibirum” transfer demands, the theory suggests that Others will not resist them. We find that the observed average earnings of DMs are substantially greater than that predicted by the 
efficient, subgame perfect equilibrium of our game. Furthermore, subjects' forecasts of the RFB are remarkably accurate. We also find that the probability of resistance is smaller in later periods of a session than in earlier ones. Nevertheless, the probability of resisting transfer demands is rather high relative to that predicted by the theory, even in the later periods of a session. Finally, we find that the probability of cooperating to resist coercion decreases as the obstacles to cooperation increase, as evidenced by the decline in the probability of resistance when the threshold is increased from 13 to 29 francs.

Regarding the topic of this conference, we find that laboratory subjects, despite the predictions of the theory, are indeed able to cooperate in resisting coercion despite the social dilemma inherent in this game. In a related study provided for this conference, Cettolin and Riedl (2011) investigate the incidence of the free-rider problem when one member of a group is singled out to make a mandatory minimum contribution to the group fund of a public goods game. In standard public goods games, some people appear to cooperate when they perceive others doing so and refuse to cooperate when they perceive others failing to do so. Such behavior is referred to in the literature as cooditional cooperation. Cettolin and Riedl are interested to know whether coodinational cooperators will make voluntary contributions to the public good when a member of the group is coerced to make a contribution to the public good. They find that coerced cooperation does not significantly affect voluntary contributions to the public good by the non-coerced members of the group. Thus, interestingly, coerced "cooperation" does not appear to mitigate the coordination problem that underlies the free-rider problem. In other words, reciprocal cooperation by conditional cooperators appears to require others in the group to take voluntary actions.

We believe that our findings make an important contribution to the public finance 
literature, not only from an academic perspective but also from a policy perspective. Our findings are consistent with anecdotal evidence that people find it very difficult to cooperate in resisting unpopular legislation in democratic states and even more so in the case of authoritarian and despotic regimes. In fact, our finding that increasing the resistance threshold makes successful resistance more difficult to achieve suggests that the more despotic the regime the less likely it will be that people can successfully cooperate to resist it. In effect, a despotic regime increases the resistance threshold to government action allowing it to take extraordinarily coercive actions against the populous. History is repleat with examples of despotic regimes, even ones engaged in the mass extermenation of the population, which apparently could only be resisted, if at all, through foreign intervention to overthrow the regime. Examples of such regimes include Hitler’s Germany and Pol Pot’s Cambodia.

Our findings suggest future research. Our DM is a randomly assigned dictator who may impose a reallocation of initial endowments, though Others have the option of avoiding redistribution by contributing to a resistance fund. Future research could investigate how appointment of the DM, including democratic election, impact behavior in this game. In addition, coordination mechanisms such as cheap talk or a credible pre-commitment device may have a profound impact on the ability to resist unfavorable policies. 


\section{APPENDIX}

\section{General Instructions}

You have been asked to participate in a decision-making experiment. It is very important that you not talk or communicate with others throughout the experiment. The instructions which we have distributed to you are solely for your private information. If you have any questions, please ask a monitor.

During the experiment your entire earnings will be calculated in francs. At the end of the experiment the total amount of francs you have earned will be converted to dollars at the following rate:

$$
5 \text { francs }=1 \text { dollar }
$$

At the end of the experiment your entire earnings from the experiment and the $\$ 2$ bonus if you arrived on time will be paid to you immediately in cash. You will also be asked to complete a pre-experiment questionnaire before making any decisions as well as a post-experiment questionnaire and for doing so, you will receive $\$ 4$.

The experiment is divided into different periods. In all, the experiment consists of 10 periods. In each period the participants are divided into groups of five. You will therefore be in a group with 4 other participants. Your group will consist of the same five participants throughout the experiment.

The remainder of the instructions explains exactly how the experiment is conducted. Remember that we ask that you avoid talking, signaling, or making noises to other participants at any time.

\section{Specific Instructions}

In the experiment today all members of your group will be endowed with 25 francs. One group member is referred to as the "Decision-Maker or DM" and the remaining four group members as "Others." At this time no one knows who the DM is for your group (even the experimenters). It could be that you will be the DM, as we will soon describe.

At the beginning of a period the DM for your group will propose how many francs each of the Others will transfer to him/her. The proposed transfer is the same for all 4 group members. If you are an Other, after you are informed of the proposed transfer to the DM you must decide whether you will voluntarily transfer the francs to the DM or resist the transfer. If you do not want to pay the transfer asked by the DM you can pay any number of francs into a Fund for your group. Each period the experimenter will add together the contributions to the Fund made by members of your group. If in a period the Fund has 13 or more francs, the transfer to the DM is not paid. But, if the Fund has less than 13 francs, you lose your contribution to the Fund and also must pay the transfer to the DM. 
Here are the two alternatives:

1. The Fund has a total of 13 or more francs. None of the Others has to transfer francs to the DM and the DM receives nothing for the period. The Others keep all francs they did not pay into the Fund. This alternative is summarized as follows, where $\mathrm{c}=$ an Other's contribution to the Fund:

When Fund $\geq 13$, Other's Earnings $=25-\mathrm{c}$ and DM Earnings $=25$.

Note: The contribution to the fund by each Other is their own private decision and can be the same or different from the contributions of other group members. Thus, each Other group member potentially has a different contribution (c) and different earnings.

2. The Fund has a total of less than of 13 francs. The francs paid into the Fund are lost and all Others must pay the transfer proposed by the DM. If an Other does not have sufficient funds remaining to fulfill the DM's proposal, the member transfers all remaining francs to the DM. The DM receives the transfer proposed (or somewhat less if a group member has insufficient funds). This alternative is summarized as follows, where c $=$ an Other's contribution to the Fund and $\mathrm{T}=$ transfer proposed by DM:

When Fund $<13$, Others Earnings $=25-\mathrm{T}-\mathrm{c}$ and DM Earnings $=4 * \mathrm{~T}+25$

In addition to the earnings decisions above, each period all group members will receive 1 franc per period to forecast the total contribution to the Fund by their group members.

The experimenter has randomly determined both group membership and which member of the group will be the DM. After the instructions are complete the experimenter will distribute decision forms to each participant here today. If your decision form is for the Decision-Maker you are the randomly selected DM for your group. Otherwise, your form will indicate you are an Other. Please do not reveal your role to other participants at any time. Also, recall that the experiment includes 10 periods.

\section{Decisions}

Please refer to the Practice Decision Forms included with these instructions.

Each period will proceed as follows:

1. Each DM will record their proposed transfer (T) in column (3) from each of the Other four group members and make a forecast of the Total Fund balance in column (5) of the DM’s Decision Form. All participants' folders will then be collected.

2. The experimenter will record the proposed transfer $(\mathrm{T})$ in column (3) of the Others Decision Forms and return folders to all participants. 
3. The Other Group Members will then record their contributions to the Fund in column (4) of their Decision Forms and also record in column (5) of their decision form the total group contribution expected this period to the Fund. Again the experimenter will collect all folders.

4. The total Fund balance for each group will be computed and recorded in column (6) of the Others' Record Sheets and column (6) of the DM's. The experimenter will return the folders and all participants will compute their period earnings in the final column.

After a period concludes, we move to the next period with the DM recording their proposed transfer ( $\mathrm{T}$ ) from each group member and repeat all steps above.

Do you have any questions?

Before we begin the experiment we will complete the practice exercises below, as well as a short pre-experiment questionnaire. Then the experimenter will distribute a folder to each participant in the room. Again, if you are the randomly selected DM for your group, the Decision Form will so indicate. Otherwise, the form will indicate that you are an Other. Your role today will not be revealed to anyone in the room. Recall that group membership and the DM were randomly determined by the experimenter.

\section{Practice Exercises}

Now we will complete the practice exercises. You will complete them for an Other as well as for a DM.

1. In the first period the DM proposes a transfer of 20 francs. One Other offers resistance (c) of 4 francs. The Fund balance is 11 francs. Compute each Practice Decision Form.

2. In the second period the DM proposes a transfer of 2 francs. One Other offers resistance (c) of 10 francs. The Fund balance is 36 francs. Compute each Practice Decision Form.

We will now distribute the folders and give the DMs 5 minutes to determine their proposed transfers for period 1 . 
DECISION FORM

Others

\begin{tabular}{|c|c|c|c|c|c|c|}
\hline $\begin{array}{c}(1) \\
\text { Period }\end{array}$ & $\begin{array}{c}(2) \\
\text { Beginning } \\
\text { balance } \\
\text { Francs }\end{array}$ & $\begin{array}{c}\text { (3) } \\
\text { Transfer } \\
\text { proposed by } \\
\text { your DM } \\
\text { (T) }\end{array}$ & $\begin{array}{c}\text { (4) } \\
\text { Your } \\
\text { contribution to } \\
\text { the Fund } \\
\text { (c) }\end{array}$ & $\begin{array}{c}\text { (5) } \\
\text { Your "Forecast" } \\
\text { of } \\
\text { Total Fund } \\
\text { balance }\end{array}$ & $\begin{array}{c}\text { (6) } \\
\text { Actual } \\
\text { Total Fund } \\
\text { balance }\end{array}$ & $\begin{array}{c}\text { (7) } \\
\text { Earnings* }\end{array}$ \\
\hline 1 & 25 & & & & & \\
\hline 2 & 25 & & & & & \\
\hline 3 & 25 & & & & & \\
\hline 4 & 25 & & & & & \\
\hline 5 & 25 & & & & & \\
\hline 6 & 25 & & & & & \\
\hline 7 & 25 & & & & & \\
\hline 8 & 25 & & & & & \\
\hline 9 & 25 & & & & & \\
\hline 10 & 25 & & & & & \\
\hline \multicolumn{7}{|c|}{ Total earnings in dollars [sum of column (7) divided by 5] } \\
\hline \multicolumn{7}{|c|}{ Forecast earnings in dollars [1 franc for each forecast in column (5) divided by 5] } \\
\hline \multicolumn{7}{|c|}{ Add $\$ 2$ bonus if on time } \\
\hline \multicolumn{5}{|c|}{ Add \$4 for completion of the pre and post-experiment questionnaires } & & \\
\hline
\end{tabular}

* Earnings each period are determined as follows:

When Fund $\geq 13, \quad$ Your Earnings $=25-\mathrm{c}$

Fund $<13, \quad$ Your Earnings $=25-\mathrm{T}-\mathrm{c}$ 
DECISION FORM

Decision-maker (DM)

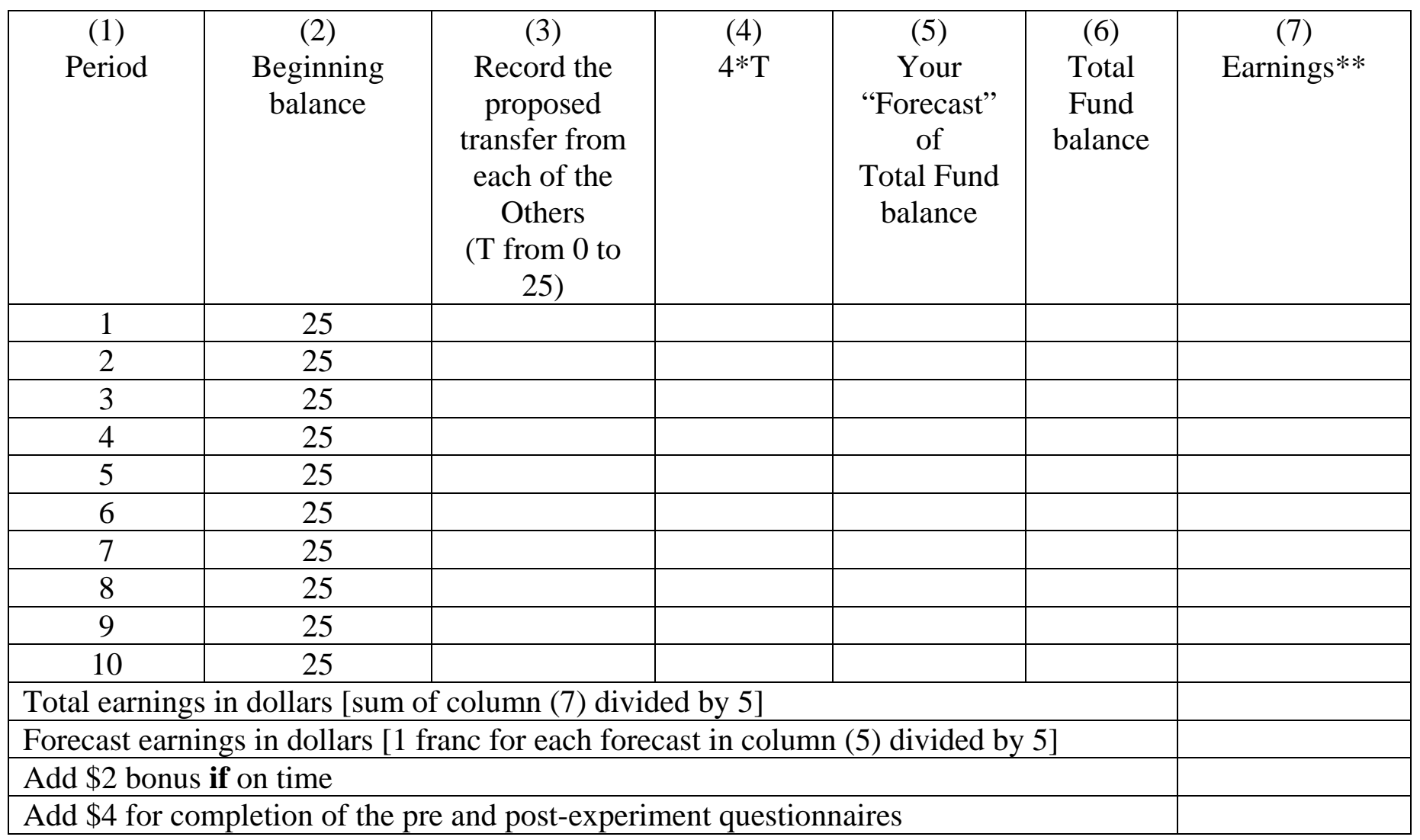

** Earnings each period are determined as follows:

When Fund $\geq 13, \quad$ Your Earnings $=25$

Fund $<13, \quad$ Your Earnings $=4 * \mathrm{~T}+25$ 
Practice DECISION FORM: Others

\begin{tabular}{|c|c|c|c|c|c|c|}
\hline $\begin{array}{c}(1) \\
\text { Period }\end{array}$ & $\begin{array}{c}(2) \\
\text { Beginning } \\
\text { balance }\end{array}$ & $\begin{array}{c}\text { (3) } \\
\text { Transfer } \\
\text { proposed by } \\
\text { your DM } \\
\text { (T) }\end{array}$ & $\begin{array}{c}\text { (4) } \\
\text { Your } \\
\text { contribution to } \\
\text { the Fund } \\
\text { (c) }\end{array}$ & $\begin{array}{c}\text { (5) } \\
\text { Your "forecast” } \\
\text { of } \\
\text { Total Fund } \\
\text { balance }\end{array}$ & $\begin{array}{c}(6) \\
\text { Actual } \\
\text { Total } \\
\text { Fund } \\
\text { balance }\end{array}$ & $\begin{array}{c}\text { (7) } \\
\text { Earnings* }\end{array}$ \\
\hline 1 & 25 & & & & & \\
\hline 2 & 25 & & & & & \\
\hline \multicolumn{7}{|c|}{ Total earnings in dollars [sum of column (7) divided by 5] } \\
\hline \multicolumn{7}{|c|}{ Forecast earnings in dollars [1 franc for each forecast in column (5) divided by 5] } \\
\hline \multicolumn{5}{|c|}{ Add $\$ 2$ bonus if on time } & & \\
\hline \multicolumn{5}{|c|}{ Add $\$ 4$ for completion of the pre and post-experiment questionnaires } & & \\
\hline
\end{tabular}

* Earnings each period are determined as follows:

When Fund $\geq 13, \quad$ Your Earnings $=25-\mathrm{c}$

Fund $<13, \quad$ Your Earnings $=25-\mathrm{T}-\mathrm{c}$

Practice DECISION FORM: Decision-maker (DM)

\begin{tabular}{|c|c|c|c|c|c|c|}
\hline $\begin{array}{c}(1) \\
\text { Period }\end{array}$ & $\begin{array}{c}(2) \\
\text { Beginning } \\
\text { balance }\end{array}$ & $\begin{array}{c}\text { (3) } \\
\text { Record the } \\
\text { proposed } \\
\text { transfer from } \\
\text { each of the } \\
\text { Others } \\
\text { (T from } 0 \text { to } \\
25)\end{array}$ & $\begin{array}{l}(4) \\
4 * T\end{array}$ & $\begin{array}{c}\text { (5) } \\
\text { Your } \\
\text { "Forecast" } \\
\text { of } \\
\text { Total Fund } \\
\text { balance }\end{array}$ & $\begin{array}{c}\text { (6) } \\
\text { Total } \\
\text { Fund } \\
\text { balance }\end{array}$ & $\begin{array}{c}(7) \\
\text { Earnings** }\end{array}$ \\
\hline 1 & 25 & & & & & \\
\hline 2 & 25 & & & & & \\
\hline \multicolumn{6}{|c|}{ Total earnings in dollars [sum of column (7) divided by 5] } & \\
\hline \multicolumn{6}{|c|}{ Forecast earnings in dollars [1 franc for each forecast in column (5) divided by 5] } & \\
\hline \multicolumn{6}{|c|}{ Add $\$ 2$ bonus if on time } & \\
\hline \multicolumn{6}{|c|}{ Add \$4 for completion of the pre and post-experiment questionnaires } & \\
\hline
\end{tabular}

** Earnings each period are determined as follows:

When Fund $\geq 13, \quad$ Your Earnings $=25$

Fund $<13, \quad$ Your Earnings $=4 * \mathrm{~T}+25$ 


\section{Pre-Experiment Questionnaire}

This questionnaire is designed to collect information to help the researchers understand decisions made throughout the experiment. Please be assured that you cannot be personally identified from your responses. You will be paid to complete the questionnaire, so please be sure to fill it out completely.

List five words that best describe who you are:

1.

2.

3.

4.

5.

\section{Post-Experiment Questionnaire}

This questionnaire is designed to collect information to help the researchers understand decisions made throughout the experiment. Please be assured that you cannot be personally identified from your responses. You will be paid to complete the questionnaire, so please be sure to fill it out completely. Please double check to ensure that you have not inadvertently skipped a question when you are finished and answer all questions as fully as possible.

1. What is your standing in your university? (check one) undergraduate student masters student

Ph.D. student Other

2. Based on your current standing (i.e., undergrad, masters, Ph.D.), what is your year of study (e.g., $\left.1^{\text {st }}, 2^{\text {nd }}, 3^{\text {rd }}, 4^{\text {th }}\right)$ ?

3. What is your college (e.g., management, education?)

4. What is your major area of concentration (e.g., accounting, biology)?

5. What is your sex? (check one) male female

6. What is your age? years 
7. What is your race/ethnicity? (check one)

Black (not if Hispanic origin) ___ White (not of Hispanic origin) Hispanic

Asian or Pacific Islander American Indian or Alaska Native

Other (please detail)

8. How would you characterize your current economic situation? (circle number)

Poor

$$
\text { 1----2----3-----4----5-----6----7----8----9----10----11 Wealthy }
$$

9. How interesting did you find this experiment?

$$
\begin{array}{lll}
\text { Not Very } & & \text { Very } \\
\text { Interesting } & \text { 1----2-----3----4----5----6-----7----8----9----10----11 } & \text { Interesting }
\end{array}
$$

10. How would you characterize the amount of money earned in this experiment for the time required?

Nominal

Amount

1----2----3----4----5-----6----7----8-----9----10----11

11. In general, how would you characterize your political attitudes?

Very

Liberal

1----2----3----4----5-----6----7----8----9----10----11

Very

Conservative

12. In general, how would you characterize your religious beliefs?

Not Religious

At All

1----2----3----4----5-----6----7----8----9----10----11

Very

Religious

13. How would you characterize your behavior today?

Very

Selfish

1----2-----3----4-----5----6-----7----8----9----10----11

Very

Generous

14. How would you characterize the decisions of your group?

Very

Selfish

$$
\text { 1----2-----3----4----5-----6----7----8----9----10----11 }
$$

Very

Generous

15. How would you characterize people, in general?

Very Selfish

$$
\text { 1----2----3-----4----5-----6----7----8-----9----10----11 }
$$

Very

Generous

16. Are you married? (check one) yes no

If not, are you in a committed relationship? (check one) yes no

17. How many children do you have?

18. What is your religious affiliation? 
19. How important are groups for you in general?

Not at all 1----2----3----4----5----6----7----8----9----10----11 To a great extent

20. Are you feeling happy today?

Not at all 1----2-----3----4----5----6----7----8----9----10----11 To a great extent

21. Please give a brief statement on what you think about groups in general and what your experiences (positive or negative) are.

22. How would you characterize your Decision-maker's (DM's) behavior today?

Check if you were the DM: N/A

Very

selfish

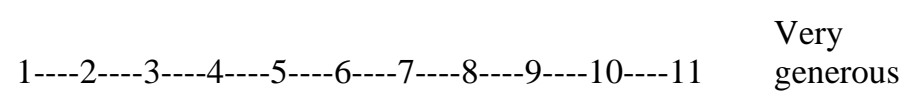

23. How would you characterize your Other group members' behavior today?

Very

cooperative 1-----2----3----4-----5----6----7----8----9----10----11

Very

uncooperative 


\section{REFERENCES}

Cettolin, Elena and Arno Riedl (2011). "Partial coercion and beliefs in voluntary contributions to public goods.” In this volume.

Congleton, Roger (2011). “Coercion, Taxation, and Voluntary Association.” working paper.

Ledyard, John (1995). "Public goods experiments”. In Kagel, John H., Roth, Alvin E. (eds.), Handbook of Experimental Economics. Princeton, NJ: Princeton University Press, pp. 111-94.

Martinez-Vazquez, Jorge and Saloua Sehili (2011). "Lindahl net fiscal incidence: An application at the regional level.” working paper.

Mertins, Vanessa (2008). "Procedural satisfaction matters - Procedural fairness does not: An experiment studying the effects of procedural judgments on outcome acceptance.” Institute for Labour Law and Industrial Relations in the European Community, IAAEG Discussion Paper No. 2008/07.

Skaperdas, Stergios (2011). "Proprietary public finance: It’s emergence \& evolution out of anarchy.” working paper.

Wallis, John (2011). "The constitution of coercions: an extension of Wicksellian thinking about violence and the ordering of society." working paper.

Winer, Stanley L., George Tridimas, and Walter Hettich (2011). "Social welfare and coercion in public finance.” working paper. 
TABLE 1: Summary Statistics

\begin{tabular}{|c|c|c|c|c|c|c|c|c|c|c|c|c|}
\hline \multirow{3}{*}{ Variables } & \multicolumn{6}{|c|}{ Others } & \multicolumn{6}{|c|}{ Decision-makers } \\
\hline & \multicolumn{2}{|c|}{ All } & \multicolumn{2}{|c|}{ Treatment 1} & \multicolumn{2}{|c|}{ Treatment 2} & \multicolumn{2}{|c|}{ All } & \multicolumn{2}{|c|}{ Treatment 1} & \multicolumn{2}{|c|}{ Treatment 2} \\
\hline & Mean & Std dev & Mean & Std dev & Mean & Std dev & Mean & Std dev & Mean & Std dev & Mean & Std dev \\
\hline Transfer demand (francs) & - & - & - & - & - & - & 9.85 & 6.49 & 8.74 & 6.42 & 11.40 & 6.34 \\
\hline Contribution to resistance fund (francs) & 4.02 & 3.91 & 3.39 & 3.05 & 4.89 & 4.73 & - & - & - & - & - & - \\
\hline Forecast of resistance fund balance (francs) & 18.23 & 17.17 & 15.27 & 10.63 & 22.37 & 22.82 & 16.46 & 8.78 & 13.82 & 7.41 & 20.15 & 9.26 \\
\hline Forecast error (francs) & 1.95 & 17.22 & 1.47 & 10.04 & 2.61 & 23.88 & 0.29 & 10.97 & 0.11 & 7.84 & 0.57 & 14.33 \\
\hline Period earnings (francs) & 17.11 & 5.87 & 19.48 & 4.21 & 13.79 & 6.24 & 40.25 & 21.47 & 33.5 & 14.22 & 49.7 & 26.00 \\
\hline Percent of transfer demands resisted & 46 & 4.9 & 56 & 4.9 & 33 & 4.7 & - & - & - & - & - & - \\
\hline Age & 24 & 6.2 & 22 & 43 & 25 & 7.9 & 24 & 7.29 & 21 & 2.69 & 27 & 10.02 \\
\hline Age-squared & 594 & 372 & 511 & 246 & 710 & 474 & 616 & 443 & 465 & 130 & 827 & 612 \\
\hline Number of years of university education & 0.03 & 0.17 & 1.02 & 0.15 & 0.04 & 0.20 & - & - & 1 & - & - & - \\
\hline Percent black & 23 & 4.2 & 27 & 4.5 & 17 & 3.7 & - & - & - & - & - & - \\
\hline Percent white & 48 & 5.0 & 47 & 4.9 & 50 & 5.0 & 79 & 4.1 & 88 & 3.3 & 67 & 4.8 \\
\hline Percent hispanic & 3 & 1.8 & 2.3 & 1.7 & 4 & 2.0 & - & - & - & - & - & - \\
\hline Percent asian & 21 & 4.0 & 17 & 3.8 & 25 & 4.3 & 14 & 3.5 & 12 & 3.3 & 17 & 3.8 \\
\hline Percent other races & 5 & 2.2 & 5 & 2.3 & 4 & 2.0 & 7 & 2.6 & 0 & 0 & 17 & 3.8 \\
\hline Percent Christian & 50 & 5.0 & 59 & 4.9 & 36 & 4.8 & 39 & 4.9 & 21 & 4.1 & 75 & 4.4 \\
\hline Percent Catholic & 9 & 2.9 & 29 & 2.4 & 14 & 3.4 & 15 & 3.5 & 21 & 4.1 & - & - \\
\hline Percent with no declared religion & 28 & 4.5 & 29 & 4.6 & 27 & 4.5 & 31 & 4.6 & 45 & 5.0 & - & - \\
\hline Percent other religions & 12 & 3.3 & 54 & 2.3 & 23 & 4.2 & 16 & 3.7 & 12 & 3.3 & 25 & 4.4 \\
\hline Percent married & 11 & 3.2 & 93 & 2.5 & 18 & 3.9 & 16 & 3.7 & - & - & 50 & 5.1 \\
\hline Percent female & 54 & 4.9 & 47 & 4.9 & 63 & 4.9 & 75 & 4.3 & 69 & 4.7 & 83 & 3.8 \\
\hline Number of observations & \multicolumn{2}{|c|}{575} & \multicolumn{2}{|c|}{335} & \multicolumn{2}{|c|}{240} & \multicolumn{2}{|c|}{144} & \multicolumn{2}{|c|}{84} & \multicolumn{2}{|c|}{60} \\
\hline
\end{tabular}


TABLE 2: Random effects model of the Decision-maker's transfer demands

\begin{tabular}{|c|c|}
\hline Variable & Estimated coefficient \\
\hline Constant & $\begin{array}{l}78.00 * * \\
(34.15)\end{array}$ \\
\hline Lagged transfer demand & $\begin{array}{c}0.249 * * \\
(0.103)\end{array}$ \\
\hline DM's forecast of resistance fund balance & $\begin{array}{l}0.0437 \\
(0.079)\end{array}$ \\
\hline Lagged forecast error & $\begin{array}{c}0.095 \\
(0.058)\end{array}$ \\
\hline $\begin{array}{l}\text { Resistance in previous period } \\
\text { (= } 1 \text { if resistance was successful in previous period) }\end{array}$ & $\begin{array}{l}-1.166 \\
(1.329)\end{array}$ \\
\hline Threshold indicator variable (= 1 if 29 francs) & $\begin{array}{l}-0.621 \\
(1.672)\end{array}$ \\
\hline Gender (= 1 if female) & $\begin{array}{l}-1.514 \\
(1.612)\end{array}$ \\
\hline Martial status (= 1 if married) & $\begin{array}{l}-2.086 \\
(14.06)\end{array}$ \\
\hline Age & $\begin{array}{l}-4.724^{*} \\
(2.606)\end{array}$ \\
\hline Age-squared & $\begin{array}{l}0.0805 \\
(0.052)\end{array}$ \\
\hline Race (= 1 if white) & $\begin{array}{l}-7.560 * * * \\
(2.340)\end{array}$ \\
\hline $\mathrm{R}^{2}$ & 0.340 \\
\hline
\end{tabular}

Number of observations

123

Clustered standard errors are reported in parentheses, clustering by 13 Decision-makers; 2 DMs are dropped because they did not report their marital status. Asterisks indicate the stastical significance of the estimated coefficient, as follows: $* * *$ indicates a p-value $<$ 0.01 ; ** indicates a p-value $<0.05$; and $*$ indicates a p-value $<0.1$. 
TABLE 3: Random effects OLS and 2SLS models of Other contributions

\begin{tabular}{|c|c|c|c|}
\hline Variables & OLS & 2SLS & 2SLS \\
\hline Constant & $\begin{array}{l}-9.619 \\
(7.611)\end{array}$ & $\begin{array}{l}-6.468 \\
(4.312)\end{array}$ & $\begin{array}{c}-2.453 \\
(1.891)\end{array}$ \\
\hline Transfer demand & $\begin{array}{c}0.219 * * * \\
(0.0242)\end{array}$ & $\begin{array}{c}-0.102 \\
(0.147)\end{array}$ & $\begin{array}{c}-0.0934 \\
(0.146)\end{array}$ \\
\hline Threshold (= 1 if 29 francs) & $\begin{array}{c}1.075 \\
(0.734)\end{array}$ & $\begin{array}{c}2.548 * * * \\
(0.743)\end{array}$ & $\begin{array}{c}2.426 * * * \\
(0.774)\end{array}$ \\
\hline Correct forecast of resistance & - & $\begin{array}{c}0.351^{* *} \\
(0.171)\end{array}$ & $\begin{array}{c}0.340 * \\
(0.177)\end{array}$ \\
\hline Age & $\begin{array}{c}0.615 \\
(0.559)\end{array}$ & $\begin{array}{c}0.413 \\
(0.317)\end{array}$ & $\begin{array}{c}0.0611 \\
(0.0553)\end{array}$ \\
\hline Age-squared & $\begin{array}{c}-0.00895 \\
(0.00980)\end{array}$ & $\begin{array}{l}-0.00627 \\
(0.00553)\end{array}$ & - \\
\hline Gender (= 1 if female) & $\begin{array}{c}0.383 \\
(0.712)\end{array}$ & $\begin{array}{c}-0.478 \\
(0.590)\end{array}$ & $\begin{array}{c}-0.341 \\
(0.473)\end{array}$ \\
\hline Marital status (= 1 if single) & $\begin{array}{c}2.251 \\
(1.747)\end{array}$ & $\begin{array}{c}1.653 \\
(1.047)\end{array}$ & $\begin{array}{c}2.203^{* *} \\
(0.996)\end{array}$ \\
\hline Number of years in college & $\begin{array}{c}-0.521 \\
(1.808)\end{array}$ & $\begin{array}{c}-0.0687 \\
(1.105)\end{array}$ & $\begin{array}{c}-0.0777 \\
(1.107)\end{array}$ \\
\hline African-American & $\begin{array}{c}-1.055 \\
(1.529)\end{array}$ & $\begin{array}{c}0.301 \\
(0.929)\end{array}$ & - \\
\hline White & $\begin{array}{c}-0.734 \\
(1.433)\end{array}$ & $\begin{array}{c}-0.325 \\
(0.823)\end{array}$ & - \\
\hline Hispanic & $\begin{array}{c}-2.372 \\
(2.624)\end{array}$ & $\begin{array}{c}0.115 \\
(1.588)\end{array}$ & - \\
\hline Asian and Pacific Islander & $\begin{array}{l}-1.507 \\
(1.547)\end{array}$ & $\begin{array}{c}0.143 \\
(1.083)\end{array}$ & - \\
\hline Protestant & $\begin{array}{c}0.995 \\
(0.832)\end{array}$ & - & - \\
\hline Catholic & $\begin{array}{c}0.877 \\
(1.520)\end{array}$ & - & - \\
\hline Other religion & $\begin{array}{c}1.299 \\
(1.212)\end{array}$ & - & - \\
\hline Number of observations & 555 & 549 & 549 \\
\hline
\end{tabular}

Clustered standard errors are reported in parentheses, clustering by the 58 Others; 2 Others are dropped because they did not report their marital status. Asterisks indicate the stastical significance of the estimated coefficient, as follows: $* * *$ indicates a p-value $<0.01$; $* *$ indicates a p-value $<0.05$; and $*$ indicates a p-value $<0.1$. 
FIGURE 1: Frequency distribution of DM's transfer demand and of successful resistance (all subjects)

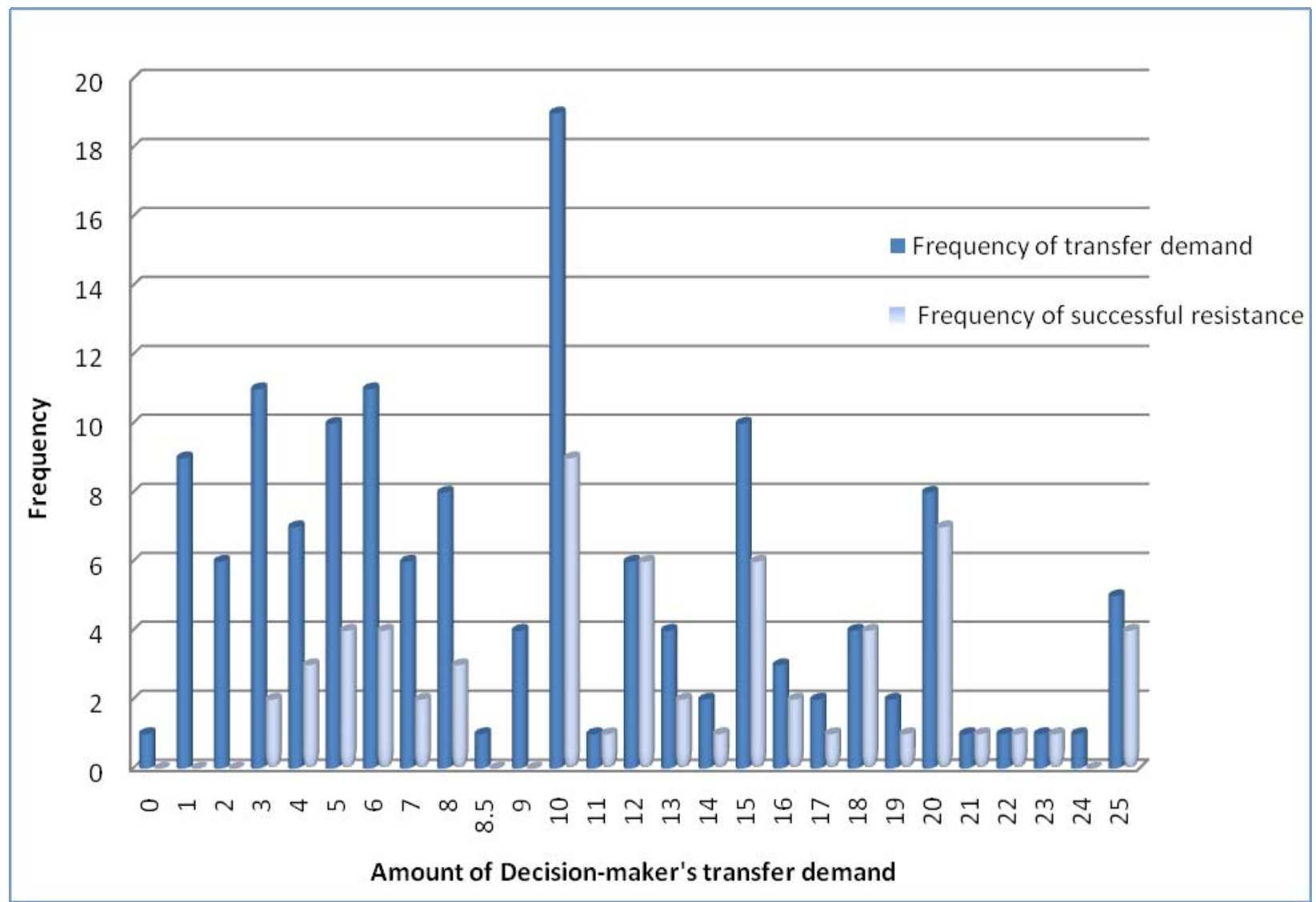

Note: This figure shows the frequency distribution of transfer demands and, conditional on the DM's transfer demand, the frequency distribution of resistance for all subjects. 
FIGURE 2: Frequency distribution of DM's transfer demand and of successful resistance (treatment 1 subjects)

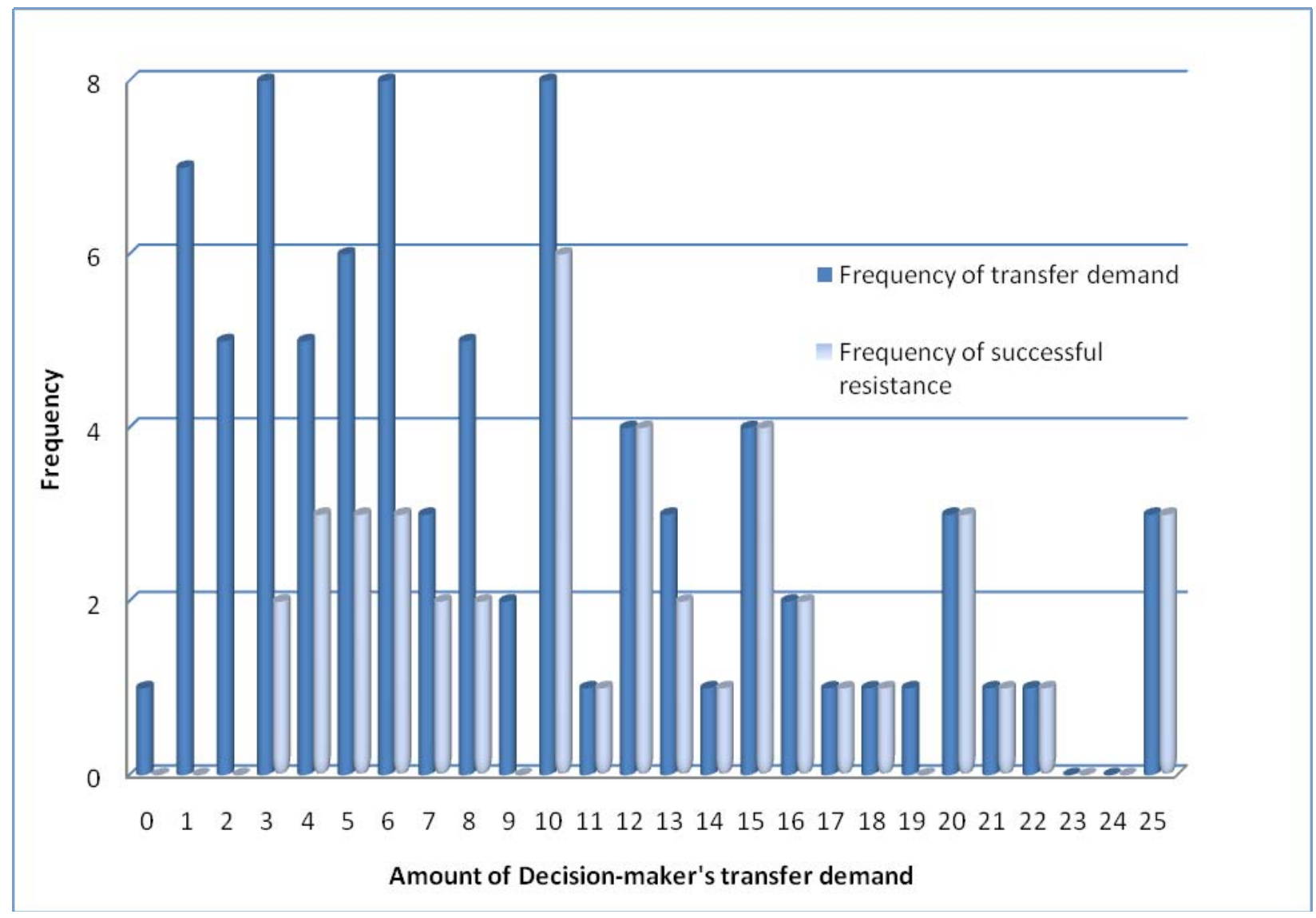

Note: This figure shows the frequency distribution of transfer demands and, conditional on the DM's transfer demand, the frequency distribution of resistance for the sample of subjects participating in treatment 1. 
FIGURE 3: Frequency distribution of DM's transfer demand and of successful resistance (subjects in treatment 2)

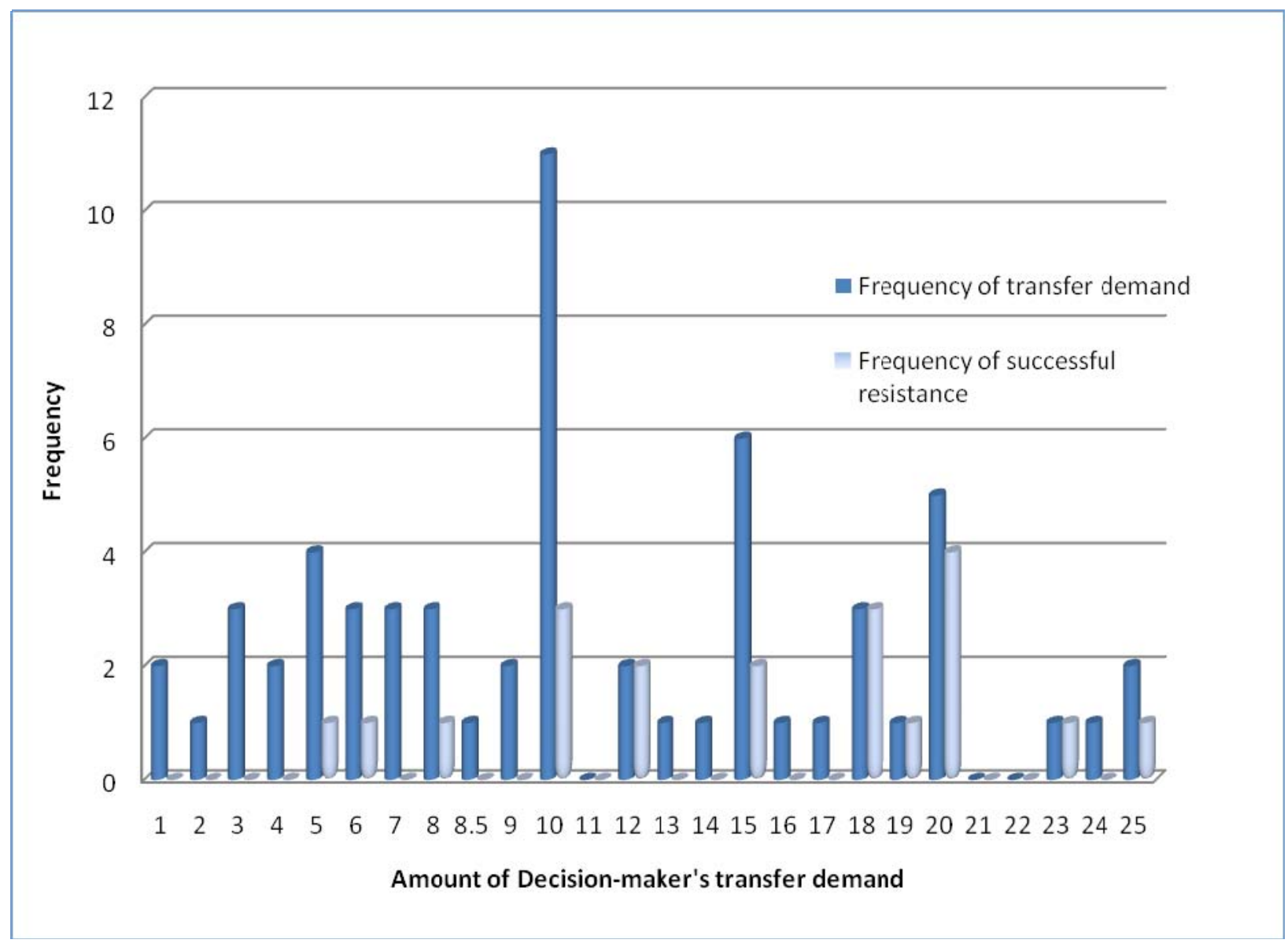

Note: This figure shows the frequency distribution of transfer demands and, conditional on theDM's transfer demand, the frequency distribution of resistance for the saample of subjects participating in treatment 2 . 
FIGURE 4: Distribution of forecast accuracy (all subjects)

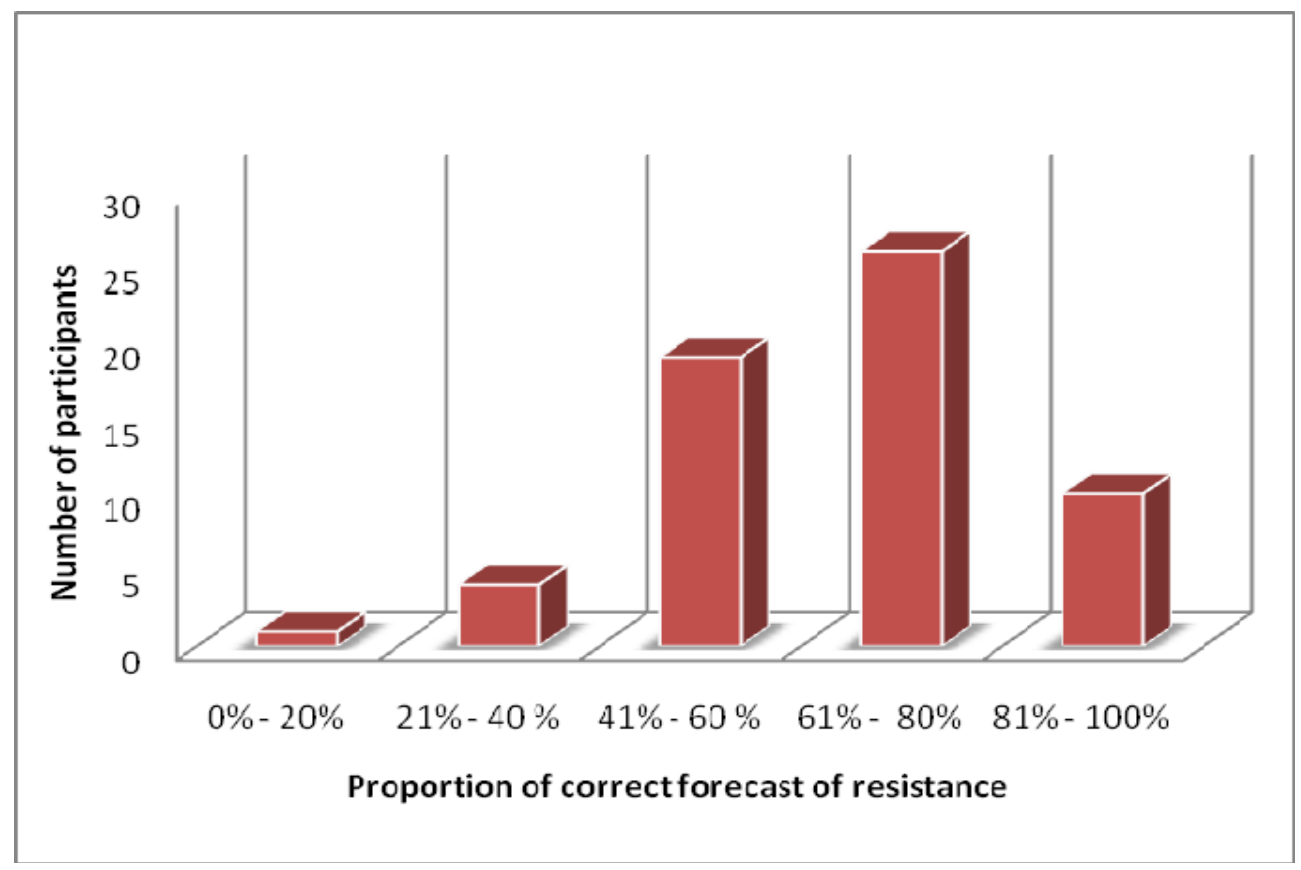


FIGURE 5: Distribution of forecast accuracy (treatment 1)

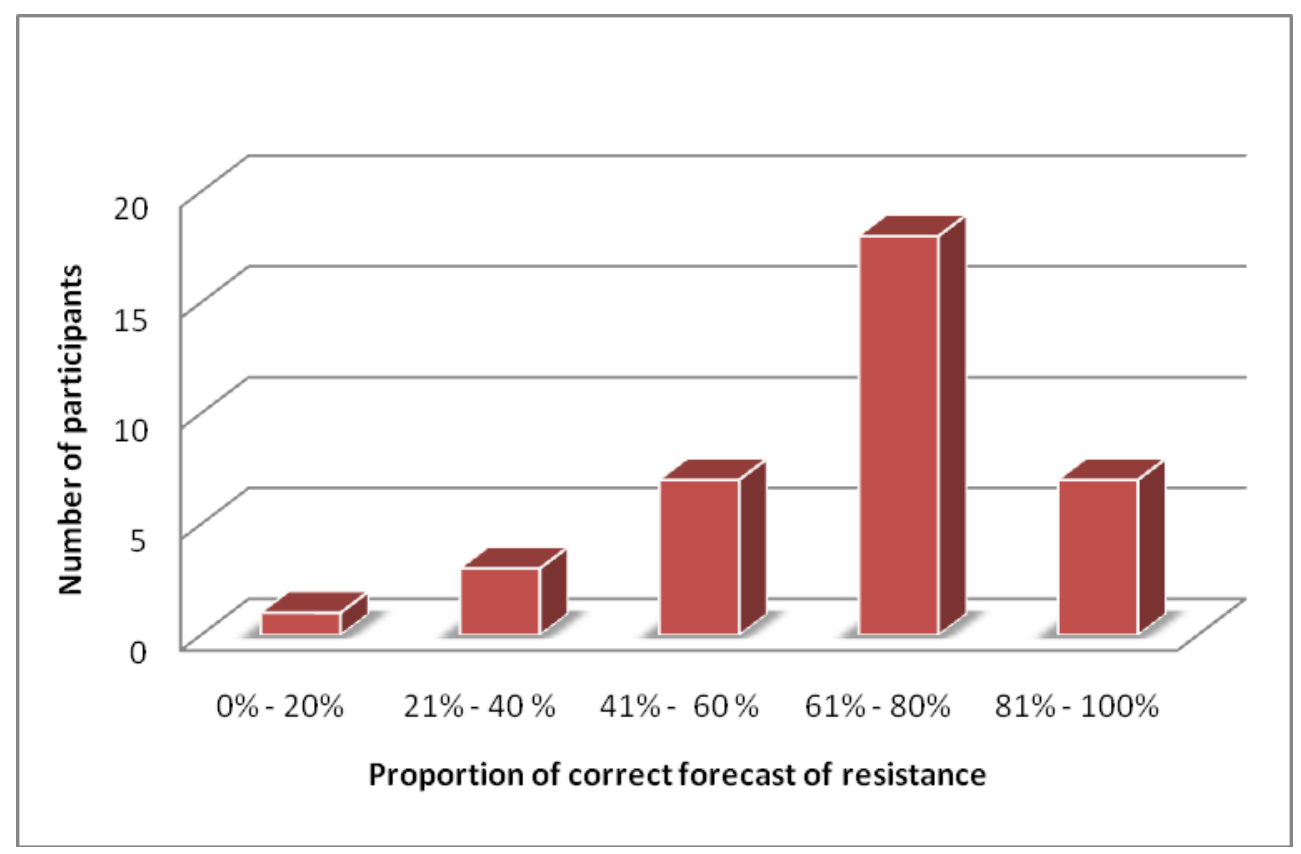

FIGURE 6: Distribution of forecast accuracy (treatment 2)

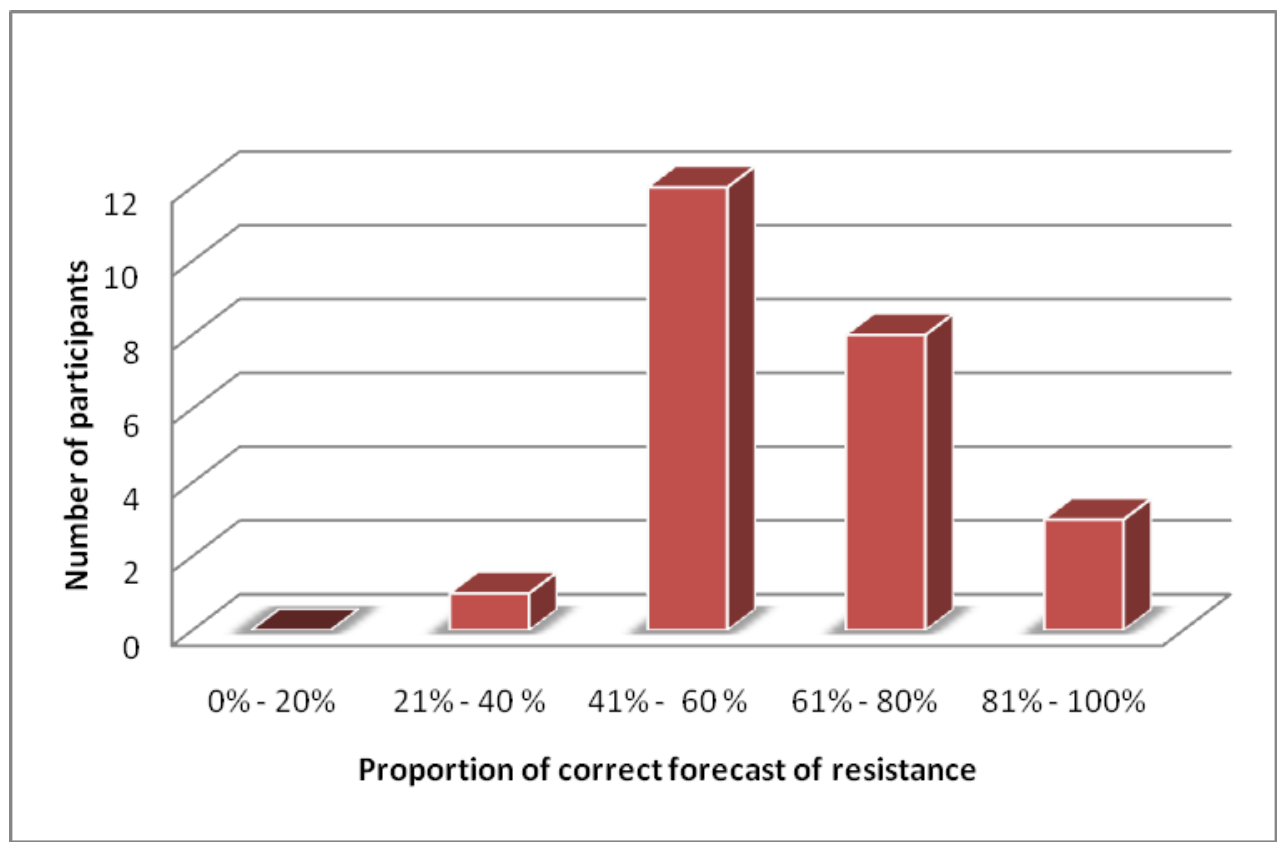

